Jurnal Jaring SainTek

Vol.1, No.1, April 2019, pp. 8-12

ISSN: 2656-9485

DOI: dx.doi.org/10.31599/jjst.v1i1.474

- 8

\title{
Studi Pengaruh Jenis Katalis, Waktu Reaksi dan Penurunan Bilangan Iodine Pada Pembuatan Cocoa Butter Substitute Dengan Proses Hidrogenasi Minyak Kelapa
}

\author{
Hernowo Widodo**1, Lisa Adhani ${ }^{2}$, Elvi Kustiyah ${ }^{3}$, Ilham Santoso ${ }^{4}$ \\ 1,2,3,4 Teknik Kimia, Fakultas Teknik, UBJ, Jakarta, Indonesia \\ e-mail: *1hernowo.widodo@dsn.ubharajaya.ac.id
}

\begin{abstract}
Abstrak
Lemak nabati dapat dipakai sebagai bahan dasar untuk membuat pengganti mentega coklat dalam pembuatan penyalut coklat. Produk yang dihasilkan ini disebut juga hard butter (mentega keras) dapat diperoleh dengan menggunakan minyak kelapa. Lemak-lemak yang digunakan sebagai pengganti mentega coklat adalah minyak kelapa, minyak sawit dan minyak inti sawit yang telah didapatkan dengan cara hidrogenasi, proses hidrogenasi digunakan untuk menurunkan bilangan iodine agar diperoleh minyak yang berbentuk padatan plastis dan untuk meningkatkan konsistensi minyak dan lemak juga untuk mengurangi warna dan bau serta untuk meningkatkan stabilitas. Pada penelitian ini Reaksi hidrogenasi minyak kelapa mengalami peningkatan kecepatan saat komposisi katalis komersial Pricat 9910 ditambahkan dengan katalis nikel sebanyak 0,75 gram dan silika sebanyak 0,75 gram yang ditandai dengan penurunan bilangan iodin yang cukup drastis yaitu dari 12,12 menjadi $1,94 \mathrm{gr} \mathrm{I}_{2} / 100 \mathrm{gr}$ contoh dalam waktu reaksi 8 jam, kandungan yang terdapat dalam minyak kelapa terhidrogenasi tidak mengalami perubahan ataupun kerusakan saat komposisi katalis yang digunakan dalam proses hidrogenasi ditingkatkan.
\end{abstract}

Kata kunci : minyak kelapa, hidrogenasi

\begin{abstract}
Vegetable fat can be used as a base for making chocolate butter substitutes in making chocolate coatings. The product is also called hard butter can be obtained using coconut oil. The fats used as a substitute for cocoa butter are coconut oil, palm oil and palm kernel oil that have been obtained by hydrogenation, the hydrogenation process is used to reduce iodine numbers to obtain oil in the form of plastic solids and to increase the consistency of oils and fats to reduce color and smell and to improve stability. In this study the hydrogenation reaction of coconut oil experienced an increase in speed when the commercial catalyst composition of Pricat 9910 was added with a 0.75 gram nickel catalyst and 0.75 grams of silica which was characterized by a drastic decrease in iodine

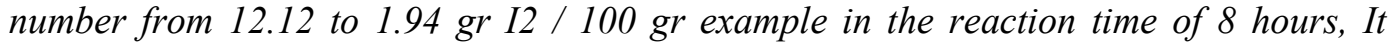
contained in hydrogenated coconut oil did not change or damage when the catalyst composition used in the hydrogenation process is increased.
\end{abstract}

Keywords: Coconut oil, hydrogenation

Received 20 Okt 2018; Revised 5 Des 2018; Accepted 15 April 2019 


\section{PENDAHULUAN}

Proses reaksi hidrogenasi katalitik minyak nabati memungkinkan minyak cair dikonversikan menjadi solid dan semi solid dengan konsistensi tertentu yang sesuai dengan untuk aplikasi margarin dan shortening. Proses ini terdiri dari pemanasan dengan adanya hidrogen elementer yang dibantu oleh suatu katalisator logam, biasanya menggunakan logam Nikel [1]. Hasil hidrogenasi ialah terjadinya penjenuhan sebagian dari ikatan tak jenuh asam lemak, isomerisasi ikatan rangkap bentuk cis (alami) menjadi bentuk trans dan perubahan posisi ikatan rangkap.

Asam lemak tidak jenuh (memiliki ikatan rangkap) yang terdapat di minyak dapat berada dalam dua bentuk yakni cis dan trans. Asam lemak tak jenuh yang terdapat di alam biasanya berada sebagai asam lemak cis, hanya sedikit bentuk trans. Jumlah asam lemak trans dapat meningkat akibat pengolahan seperti hidrogenasi, pemanasan pada suhu tinggi[2].

Dari hasil penelitian selama dekade terakhir menunjukkan dampak negatif asam lemak trans terhadap kesehatan yaitu dapat memicu penyakit jantung koroner[3]. Pada reaksi hidrogenasi terjadi pengikatan atom $\mathrm{H}$, sehingga molekul cis akan berubah menjadi molekul trans. Bentuk trans sulit mengalami efek polarisasi meski dipengaruhi oleh medan [4].

Dari penelitian sebelumnya, masih diperlukan waktu proses yang cukup lama untuk dapat menghasilkan minyak terhidrogenasi atau minyak dengan rantai ikatan tunggal atau ikatan jenuh,. Dalam penelitian ini dicoba melakukan proses reaksi hidrogenasi dari minyak kelapa (CNO), menggunakan Ni-Si sebagai katalis dan memberikan gas hidrogen secara langsung atau di permukaan katalis. Dengan menggunakan logam $\mathrm{Ni}$ dan untuk memungkinkan pasokan hidrogen terlarut di dekat lokasi dimana kontak fasa cair minyak dengan padat katalis[5].

\section{METODE PENELITIAN}

Penelitian ini dilakukan untuk melihat pengaruh komposisi katalis terhadap waktu reaksi yang diperlukan untuk mendapatkan minyak kelapa yang terhidrogenasi. penelitian ini dibagi menjadi 3 tahapan, yaitu hidrogenasi minyak kelapa, penelitian bilangan iodin sampel minyak kelapa terhidrogenasi, dan pengujian komposisi dengan alat Gas Chromatograph sampel minyak kelapa terhidrogenasi.

Ada dua pengujian yang dilakukan, yaitu penentuan bilangan iodin dan pengujian komposisi dari minyak kelapa terhidrogenasi. Penentuan bilangan iodin dilakukan dengan menggunakan metode Wijs. Perubahan komposisi juga diamati dengan cara menguji komposisi sampel dengan alat Gas Chrommatograph.

Adapun prosedur hidrogenasi minyak kelapa yaitu timbang minyak kelapa yang direaksikan sebanyak $1400 \mathrm{ml}$ kemudian timbang katalis yang digunakan, yaitu Pricat 9910 seberat 1.4 gr lalu ambilkan sebagian dari minyak kelapa yang sudah ditimbang untuk melarutkan katalis yang sudah ditimbang kemudian masukkan minyak kelapa dan katalis ke dalam reactor lalu panaskan reaktor hingga mencapai suhu yang diinginkan dengan mengatur suhu pada pemanas listrik lebih tinggi $\pm 10^{\circ} \mathrm{C}$ dari suhu yang diinginkan di dalam reactor kemudian hidupkan pendingin air agar suhu yang telah tercapai dapat terjaga kondisinya lalu diinjeksikan gas hidrogen ke dalam reaktor secara kontinyu dengan tekanan sebesar 3 bar tekanan diketahui dari pressure gauge kemudian kontrol suhu, tekanan dan laju alir gas hidrogen selama durasi waktu hingga mendapatkan bilangan iodin dibawah 1 (satu) kemudian lakukan reaksi hidrogenasi minyak kelapa dengan variasi komposisi katalis Ni dan Si selama 4, 6, 8 jam. 


\section{HASIL DAN PEMBAHASAN}

Volum titran blanko yang digunakan sebagai scuan adalah $40.80 \mathrm{ml}, 40.90 \mathrm{ml}$, $40.70 \mathrm{ml}, 40.50 \mathrm{ml}$. Blangko yang digunakan berbeda dikarenakan pengujian yang dilakukan tidak pada hari yang sama. Blangko adalah larutan reagen Wijs, reagen Cyclohexane dan reagen Magnesium Asetat 5\% tanpa diberikan sampel minyak kelapa terhidrogenasi.

Tabel 1. Hasil Uji Penentuan Bilangan Iodin Minyak Kelapa Terhidrogenasi

\begin{tabular}{|c|c|c|c|c|c|c|}
\hline \multicolumn{4}{|c|}{ Variabel } & \multicolumn{4}{c|}{ Waktu (Jam) } \\
\hline Standar (gr) & Ni (gr) & Si (gr) & 0 & 4 & 6 & 8 \\
\hline 1,4 & - & - & 12,12 & 9,3 & 4,8 & 2,76 \\
\hline 1,4 & 0,5 & - & 12,12 & 8,96 & 4,76 & 2,44 \\
\hline 1,4 & 0,75 & - & 12,12 & 8,34 & 3,98 & 2,09 \\
\hline 1,4 & 1 & - & 12,12 & 8,43 & 4,21 & 2,13 \\
\hline 1,4 & - & 0,5 & 12,12 & 9,28 & 6,95 & 3,46 \\
\hline 1,4 & - & 0,75 & 12,12 & 9,14 & 6,64 & 4,16 \\
\hline 1,4 & - & 1 & 12,12 & 9,23 & 6,21 & 3,51 \\
\hline 1,4 & 0,5 & 0,5 & 12,12 & 8,45 & 4,44 & 2,2 \\
\hline 1,4 & 0,75 & 0,75 & 12,12 & 8,26 & 3,46 & 1,94 \\
\hline
\end{tabular}

Berdasarkan tabel di atas, terjadi penurunan bilangan iodin minyak kelapa yang telah dihidrogenasi menjadi sekitar 9 dari sebelumnya 12,12. penurunan bilangan iodin terbesar diperoleh oleh sampel minyak kelapa yang dihidrogenasi dengan komposisi katalis standar yang ditambah dengan katalis nikel dan silika masing-masing 0,75 gram pada waktu 4, 6, dan 8 jam. Sedangkan, penurunan bilangan iodin terendah diperoleh oleh sampel minyak kelapa yang dihidrogenasi dengan menggunakan katalis standar yang ditambahkan dengan silika 0,5 gram.

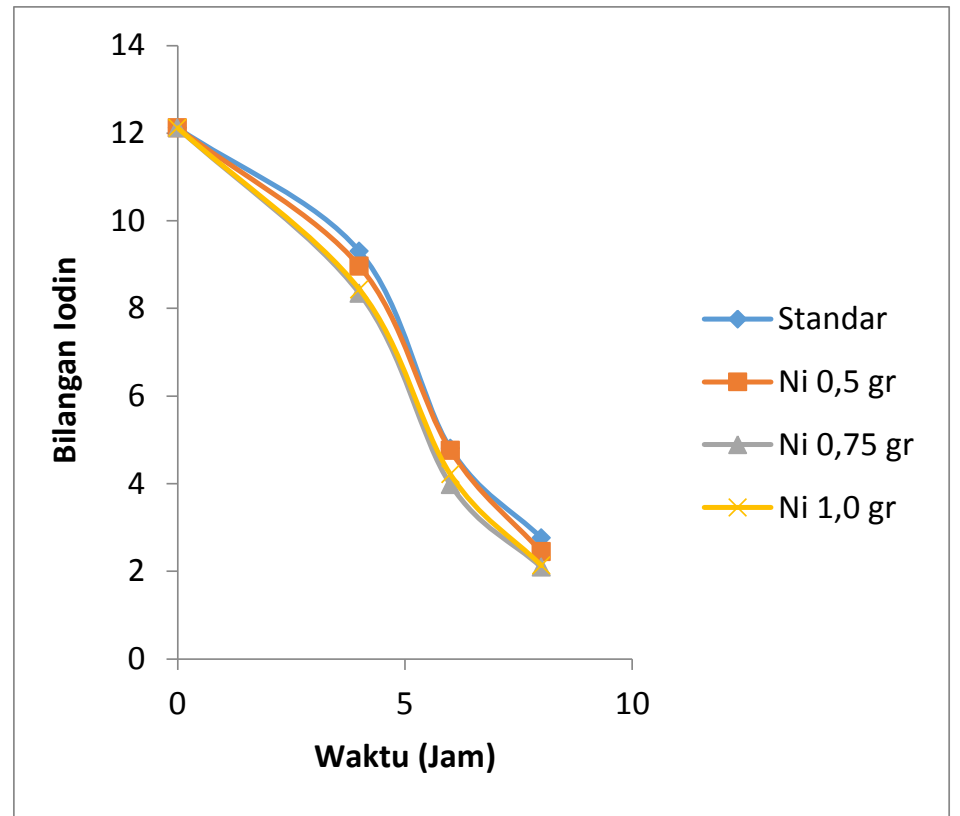

Gambar 1. Grafik Variasi Komposisi Katalis Nikel terhadap Waktu Penurunan Bilangan Iodin 
Gambar diatas menunjukkan bahwa tidak ada perubahan drastis pada penurunan bilangan iodin yang disebabkan oleh penambahan katalis nikel sebanyak 0,5 gram.

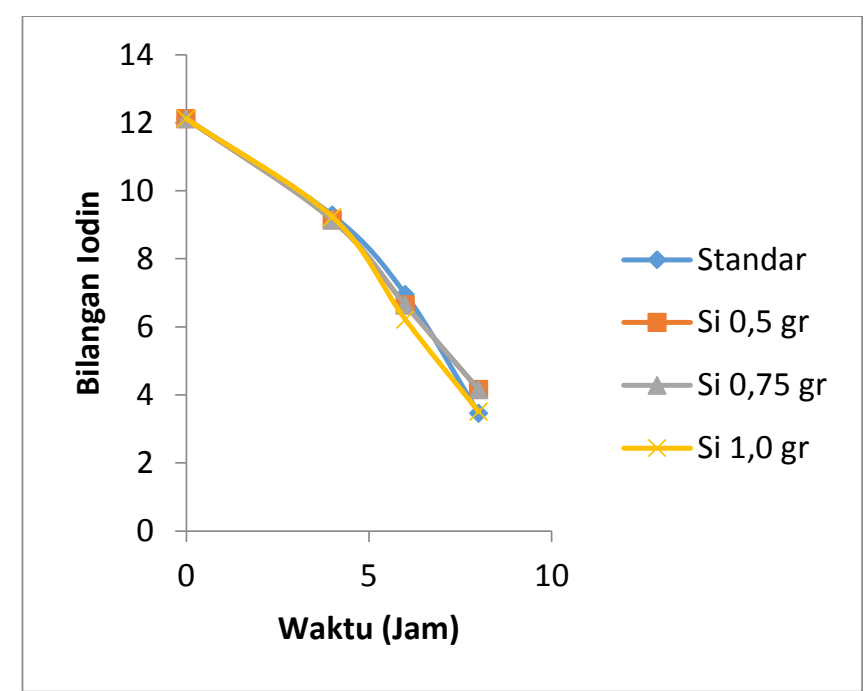

Gambar 2. Grafik Variasi Komposisi Katalis Silika terhadap Waktu Penurunan Bilangan Iodin

Gambar menunjukkan bahwa tidak ada perubahan drastis pada penurunan bilangan iodin yang disebabkan oleh penambahan katalis silika pada semua variasi yang dilakukan dalam penelitian ini. Penurunan bilangan iodin yang lebih telihat terjadi setelahproses hidrogenasi ini berlangsung6 dan 8 jam.

Penurunan bilangan iodin pada variasi katalis silika ini tidak ada perubahan drastis kemungkinan karena disebabkan silika dalam katalis ini berperan sebagai penyangga dari katalis nikel sehingga peranannya kurang signifikan dalam mempercepat reaksi hidrogenasi apabila komposisinya ditingkatkan tetapi tidak diimbangi dengan meningkatnya katalis nikel.

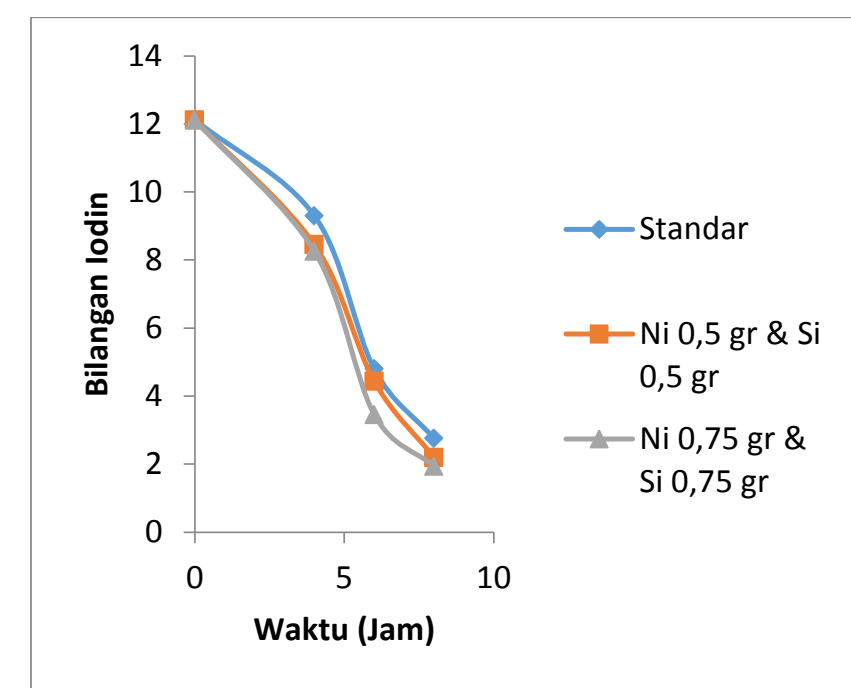

Gambar 3. Grafik Variasi Komposisi Katalis Nikel dan Silika terhadap Waktu Penurunan Bilangan Iodin

Gambar diatas menunjukkan bahwa tidak ada perubahan drastis pada penurunan bilangan iodin yang disebabkan oleh penambahan katalis nikel dan silika sebanyak 0,5 gram. Penurunan bilangan iodin terbesar pada proses hidrogenasi ini terjadi pada penambahan variasi katalis nikel dan silika sebanyak 0,75 gram. 
Penurunan bilangan iodin pada penambahan katalis nikel dan silika ini terlihat drastis saat proses reaksi telah berlangsung selana 6 jam. Hal ini disebabkan reaksi belum stabil dan masih berjalan lambat saat reaksi baru berlangsung selama 4 jam.

\section{KESIMPULAN}

Berdasarkan hasil penelitian hidrogenasi minyak kelapa dengan menggunakan katalis komersial Pricat 9910 dengan merubah komposisi katalis nikel dan silika selama 4, 6 dan 8 jam dan pembahasan yang telah diuraikan, dapat diambil kesimpulan bahwa hidrogenasi minyak kelapa dengan menggunakan katalis komersial Pricat 9910 dengan adanya perubahan komposisi atau dengan penambahan hanya katalis nikel sebanyak 0,5 gram tidak mengalami perubahan drastis terhadap kecepatan reaksihidrogenasi. Akan tetapi pada penambahan katalis nikel sebanyak 0,75 dan 1 gram terjadi perubahan kecepatan sedikit dengan ditandai penurunan bilangan iodin yang cukup besar. Hidrogenasi minyak kelapa dengan penambahan hanya katalis silika tidak mengalami perubahan yang drastis karena kemungkinan silika dalam katalis ini berperan sebagai penyangga katalis sehingga penambahannya kurang berperan dalam mempercepat reaksi. Reaksi hidrogenasi minyak kelapa mengalami peningkatan kecepatan saat komposisi katalis komersial Pricat 9910 ditambahkan dengan katalis nikel sebanyak 0,75 gram dan silika sebanyak 0,75 gram yang ditandai dengan penurunan bilangan iodin yang cukup drastis yaitu dari 12,12 menjadi 1,94 gr $\mathrm{I}_{2} / 100$ gr contoh dalam waktu reaksi 8 jam. Kandungan yang terdapat dalam minyak kelapa terhidrogenasi tidak mengalami perubahan ataupun kerusakan saat komposisi katalis yang digunakan dalam proses hidrogenasi ditingkatkan.

\section{DAFTAR PUSTAKA}

[1] Gopala, K.A.G., Raj, G., Bhatnagar, AS., Prasanth, K.P.K., dan Chandrashekar, P. (2010). Coconut Oil: Chemistry, Production and Its Applications-A Review. Indian Coconut Journal. 73(3):15-27.

[2] Silalahi, J. (2006). Fats and Oils: Modification and Substitution. Lecture Notes. Postgraduate Section. Universitas Sumatera Utara. Medan. Hal. 17-25, 63-68.

[3] Silalahi, J., dan Tampubolon, S.D.R. (2002). Asam Lemak Trans dalam Makanan dan Pengaruhnya Terhadap Kesehatan. Jurnal Teknloogi dan Industri Pangan. 8(2):184-188.

[4] O'Brien, R.D. (1998). Fats and Oils: Formulating and Processing for Applications. New York: Technomic. Hal.7-30.

[5] Paquot, C., dan Hautfenne, A. (1987). Determination of Fatty Acid in The 2Position in The Triacylglycerides of Oils and Fats. Dalam: Standard Methods of The Analysis of Oils, Fats and Derivates. Edisi VII. London: Blackwell Scientific Publication. Hal. 111-135. 